\title{
Interfacial Dielectric Losses in Co-Doped Ni-Zn Ferrites
}

\author{
G. Nicoara, M. Steflea* and M. Toacsan
}

Institute of Physics and Technology of Materials, P.O. Box MG-7, 76900 Bucharest-Magurele, Romania

* Bucharest University, Physics Department, 76900 Bucharest-Magurele, Romania

\begin{abstract}
The temperature and frequency dependence of tg $\delta$ and $\varepsilon^{\prime}$ for $\mathrm{Ni}_{0.8} \mathrm{Zn}_{0.2} \mathrm{Co}_{3} \mathrm{Fe}_{2-2}$ ferrites was studied in the $10^{2}-10^{6} \mathrm{~Hz}$ frequency range and $20-200^{\circ} \mathrm{C}$ temperature range. The experimental curves exhibit aspects very dependent of composition. To verify that interfacial losses, expected to appear in this type of system, are compatible with the experimental results a calculation of the dielectric permittivity and dielectric loss using the Koops' model was made. A good correlation between calculated and experimental curves was found.
\end{abstract}

\section{INTRODUCTION}

It is well known that the ferrites exhibit large values and strong frequency dependence of the dielectric permittivity ( $\left.\varepsilon^{\prime}\right)$.The first explanation was given by Koops[1] using a Maxwell-Wagner two-layer model. He assumed that the grains have the surface layer more or less oxidized than the bulk and a interface polarisation occurs. Generally, this model could explain very well the frequency dependent permittivity $\varepsilon^{\prime}(f)$ and the relaxation character of tg $\delta$ with a strong increase at low frequencies [24].

While the frequency dependence of $\varepsilon^{\prime}$ and tg $\delta$ were examined for different compositions system, the temperature dependencies of these parameters were less considered [2-5].

\section{RESULTS AND DISCUSSIONS}

In order to study the temperature and frequency dependence of $\varepsilon^{\prime}$ and tg $\delta$ we chose the system $\mathrm{Ni}_{0.8} \mathrm{Zn}_{0.2} \mathrm{Co}_{\mathrm{z}} \mathrm{Fe}_{2-\mathrm{z}} \mathrm{O}_{4}$ $(0 \leq z \leq 0.2)$. The samples, sintered at $1240^{\circ} \mathrm{C}$ for 8 hours in $\mathrm{O}_{2}$ atmosphere, were investigated in the $10^{2}-10^{6} \mathrm{~Hz}$ frequency range and $20-200^{\circ} \mathrm{C}$ temperature range.

The experimental curves exhibit very different aspects. In figures 1 and 2 are presented some typical curves.
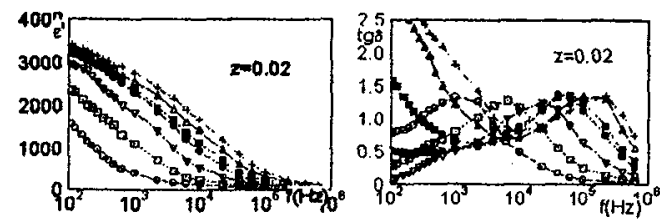

Fig. 1 Experimental $\varepsilon^{\prime}$ and $\operatorname{tg} \delta$ vs. frequency for $z=0.02$

$0-28^{\circ} \mathrm{C}, \square-68^{\circ} \mathrm{C}, \nabla-103^{\circ} \mathrm{C},-129^{\circ} \mathrm{C},-139^{\circ} \mathrm{C}, \Delta-161^{\circ} \mathrm{C}$ $+-181^{\circ} \mathrm{C}$
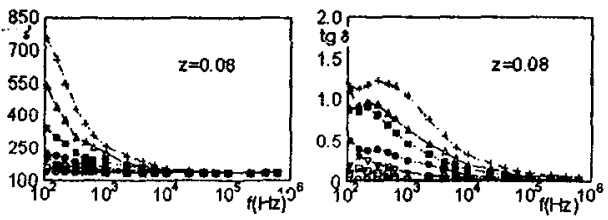

Fig. 2 Experimental $\varepsilon^{\prime}$ and $\operatorname{tg} \delta$ vs. frequency for $z=0.08$ $0-27^{\circ} \mathrm{C}, \square-68^{\circ} \mathrm{C}, \nabla-105^{\circ} \mathrm{C},-137^{\circ} \mathrm{C},-163^{\circ} \mathrm{C}, \Delta-184^{\circ} \mathrm{C}$ $+-199^{\circ} \mathrm{C}$ $2=0.08$.

For $z \leq 0.04$, the samples have the same kind of curves like $z=0.02$, while for $z>0.04$ the curves are similar to that for 
The $\varepsilon^{\prime \prime}(f)$ vs $\varepsilon^{\prime}(f)$ Cole-Cole diagrams are circular arcs at room temperature and become open arcs at higher temperatures for $z=0.02$, while for $z=0.08$ they are open arcs at all temperatures, showing the presence of interfacial losses.

Some remarks can be done:

1. $\varepsilon^{\prime}(f)$ and $\operatorname{tg} \delta(f)$ are temperature increasing functions.

2. Generally, the $\operatorname{tg} \delta(f)$ curves show several temperature-dependent maxima accompanied by a low frequency minimum above certain temperature.

3. For $z \leq 0.04$ the decrease of $\varepsilon$ 'apears on a very large frequency range and tg $\delta(f)$ maxima are very well evidenced.

4. For $z>0.04$ the decrease of $\varepsilon$ ' is faster and the $\operatorname{tg} \delta$ maxima are quite visible.

The very different forms of these curves, strongly dependent of temperature and composition, conducted us to examine whether they are all justified by the interfacial losses model.

So, the $\varepsilon^{\prime}(f, T)$ and $\operatorname{tg} \delta(f, T)$ curves were calculated on the basis of the phenomenological model of Koops[1] using the following formula:

$$
\begin{aligned}
& \varepsilon^{\prime}=(x+1) \cdot \frac{\varepsilon_{1} \rho_{1}^{2} x+\varepsilon_{2} \rho_{2}^{2}+4 \pi^{2} f^{2} \varepsilon_{0}^{2} \varepsilon_{1} \varepsilon_{2} \rho_{1}^{2} \rho_{2}^{2}\left(x \varepsilon_{2}+\varepsilon_{1}\right)}{\left(\rho_{1} x+\rho_{2}\right)^{2}+4 \pi^{2} f^{2} \varepsilon_{0}^{2}\left(\varepsilon_{1}+x \varepsilon_{2}\right)^{2} \rho_{1}^{2} \rho_{2}^{2}} \\
& \operatorname{tg} \delta=\frac{\rho_{1} x+\rho_{2}+4 \pi^{2} f^{2} \varepsilon_{0}^{2}\left(\varepsilon_{1}^{2} \rho_{1}^{2} \rho_{2}+\varepsilon_{2}^{2} \rho_{1} \rho_{2}^{2} x\right)}{2 \pi f \varepsilon_{0}\left[\varepsilon_{1} \rho_{1}^{2} x+\varepsilon_{2} \rho_{2}^{2}+4 \pi^{2} f^{2} \rho_{1}^{2} \rho_{2}^{2} \varepsilon_{0}^{2} \varepsilon_{1} \varepsilon_{2}\left(\varepsilon_{1}+\varepsilon_{2} x\right)\right]}
\end{aligned}
$$

where the subscripts 1 and 2 correspond to the surface layer and the bulk, respectively. It has been considered $\rho_{i}=A_{i} T \exp \left(q_{i} k T\right)$ the resistivities with their temperature dependence, $\varepsilon_{i}$-the permittivities of the two layers $(i=1,2)$, and $x=l_{1} l_{2}$-the ratio of their thickness.
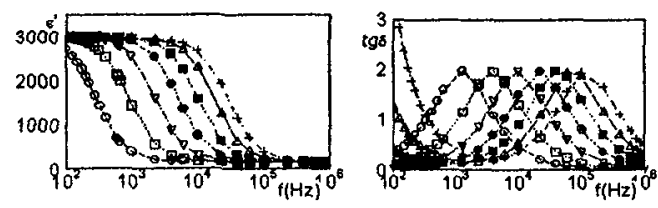

Fig. 3 Calculated $\varepsilon^{\prime}$ and $\operatorname{tg} \delta$ vs. frequency $\left(x=0,09, q_{1}=0.68 \mathrm{eV}\right.$, $\left.\mathrm{q}_{2}=0.35 \mathrm{eV}, \mathrm{A}_{1}=3 \cdot 10^{-5} \Omega \mathrm{m} / \mathrm{K}, \mathrm{A}_{2}=9 \cdot 10^{-4} \Omega \mathrm{m} / \mathrm{K}\right)$ O-20 ${ }^{\circ} \mathrm{C}, \square-50^{\circ} \mathrm{C}, \nabla-80^{\circ} \mathrm{C},-110^{\circ} \mathrm{C},-140^{\circ} \mathrm{C}, \Delta-170^{\circ} \mathrm{C}$ $+-200^{\circ} \mathrm{C}$
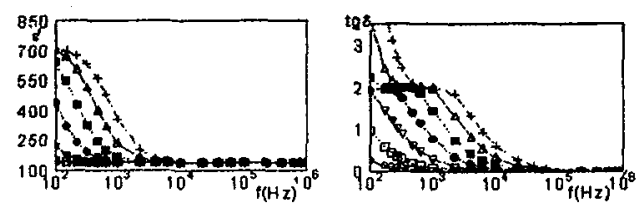

Fig.4 Calcnlated $\varepsilon^{\prime}$ and tg $\delta$ vs. frequency $\left(x=0.08, q_{1}=0.42 \mathrm{eV}\right.$, $\mathrm{q}_{2}=0.405 \mathrm{eV}, \mathrm{A}_{1}=2.5 \cdot 10^{-2} \Omega \mathrm{m} / \mathrm{K}, \mathrm{A}_{2}=2.2 \cdot 10^{-3} \Omega \mathrm{m} / \mathrm{K}$ ) $0-20^{\circ} \mathrm{C}, \square-50^{\circ} \mathrm{C}, \nabla-80^{\circ} \mathrm{C},-110^{\circ} \mathrm{C},=-140^{\circ} \mathrm{C}, \Delta-170^{\circ} \mathrm{C}$ $+-200^{\circ} \mathrm{C}$

Some of the obtained typical curves are given in figures 3 and 4. These sets of curves were chosen because of their good resemblance with those in figs. 1 and 2, respectively. The following remarks can be done:

- All types of the experimental curves can be calculated using the Koops' model;

- The $\varepsilon^{\prime}$ and $\operatorname{tg} \delta$ values comparable with the experimental ones are obtained for $0.08 \leq x \leq 0.15$.

-Curves like those in fig. 3 are obtained when the two activation energies $q_{1}, q_{2}$ are much different and $A_{1}<A_{2}$. For fig.3 $x=0.09, q_{1}=0.68 \mathrm{eV}, q_{2}=0.35 \mathrm{eV}, A_{1}=3 \cdot 10^{-5} \Omega \mathrm{m} / \mathrm{K}, A_{2}=9 \cdot 10^{-4} \Omega \mathrm{m} / \mathrm{K}$, corresponding to $\rho_{1} / \rho_{2}=\left(3.5 \cdot 10^{4}\right)$ at room temperature.

-Curves like those in fig. 4 are obtained when the two activation energies are very close and $A_{1}>A_{2}$. For the presented case $x$ $=0.08, q_{1}=0.42 \mathrm{eV}, q_{2}=0.405 \mathrm{eV}, A_{1}=2.5 \cdot 10^{-2} \Omega \mathrm{m} / \mathrm{K}, \mathrm{A}_{2}=2.2 \cdot 10^{-3} \Omega \mathrm{m} / \mathrm{K}$, with $\rho_{1} / \rho_{2}=\left(3.4 \cdot 10^{2}\right)$ at room temperature.

-The calculated $\operatorname{tg} \delta$ curves exhibit equal values of tg $\delta$ maxima, while an increase of tg $\delta$ maximum with temperature is experimentally observed for some compositions.

Excepting this last remark, which we think can be explained by a more complicate temperature dependence of resistivities, it can be concluded the used model describes quite well the interfacial losses present in the investigated compositions.

\section{REFERENCES}

1. C.G.Koops,Phys.Rev.83,121 (1951)

2.P.K.Larsen,R.Metselaar,Phys.Rev.B8,2016 (1973)

3.B.K.Kuan,,G.P.Srivastava,J.Appl.Phys.75,6115 (1994)

4.A.Largeteau,J.Ravez,Mater.Sci.Eng.B,Solid State Mater.Adv Technol.B6,33 (1990)

5.B.K.Kuanr,G.P.Srivastava,Cryst.Prop.Prep.(Switzerland)27-30,227 (1989) 